\title{
Atomic force microscopy of a ctpA mutant in Rhizobium leguminosarum reveals surface defects linking CtpA function to biofilm formation
}

\begin{abstract}
Correspondence
Tanya E. S. Dahms

tanya.dahms@uregina.ca
\end{abstract}

Received 4 May 2011

Revised 11 July 2011

Accepted 16 August 2011

\author{
Jun Dong, ${ }^{1}$ Karla S. L. Signo, ${ }^{2}$ Elizabeth M. Vanderlinde, ${ }^{2}$ \\ Christopher K. Yost ${ }^{2}$ and Tanya E. S. Dahms ${ }^{1}$ \\ ${ }^{1}$ Department of Chemistry and Biochemistry, University of Regina, Regina, SK S4S OA2, Canada \\ ${ }^{2}$ Department of Biology, University of Regina, Regina, SK S4S OA2, Canada
}

\section{INTRODUCTION}

The Gram-negative bacterial cell envelope is a complex, multi-component structure that can include a diffuse layer of exopolysaccharides (EPSs) at its exterior, a more intimately attached capsular layer of secreted polysaccharides (CPSs), followed by an outer membrane with a predominantly lipopolysaccharide (LPS) outer leaflet, a peptidoglycan cell wall and finally a cytoplasmic membrane (Lepek \& D'Antuono, 2005; Silhavy et al., 2010). The envelope is an important protective barrier preventing the entry of harmful substances into the cell. It is also important in host-bacteria interactions, representing a point of physical contact between the host cells and bacteria (Silhavy et al., 2010). During changing environmental conditions, a cell must maintain envelope function to ensure the selective passage of nutrients into the cell and waste products out of the cell.

Symbiotic bacteria, like rhizobia, are subject to a variety of changing environmental conditions and can be subjected to a variety of environmental and host-derived stresses, including desiccation, temperature fluctuations, plant immune defence response and exposure to toxic compounds secreted by plant roots or competing rhizobacteria (Vlassak \& Vanderleyden, 1997; Soto et al., 2009). Therefore, the rhizobial cell envelope must be a dynamic structure capable of adapting to changing environmental conditions.

Abbreviations: AFM, atomic force microscopy; CPS, capsular polysaccharide; EPS, extracellular polysaccharide; FS, force spectroscopy; PLL, poly-L-lysine.

Three supplementary figures are available with the online version of this paper.
Rhizobium leguminosarum, a symbiont frequently associated with peas (Pisum sativum), is a model organism for studying the rhizobial cell envelope. The outer membrane LPS and EPS of $R$. leguminosarum have been intensely studied (Carlson et al., 1999; Skorupska et al., 2006). Despite this focused research, uncharacterized genes important for envelope assembly and function continue to be reported, emphasizing that much remains to be elucidated regarding cell envelope structure and function in rhizobia. A recent example is the $\operatorname{ctp} A$ gene from $R$. leguminosarum, which was shown to play an important role in cell envelope function (Gilbert et al., 2007). Mutation of ctpA in R. leguminosarum decreased cell envelope integrity, altered cell morphology and increased desiccation sensitivity (Gilbert et al., 2007).

The CtpA protein is located in the periplasm (Hoge et al., 2011) and its biochemical function was first described in Escherichia coli in which it was shown to act as a C-terminal protease. CtpA substrates are often proteins linked to cell envelope development, for example the penicillin-binding protein 3 (FtsI) from E. coli (Hara et al., 1989, 1991) and outer-membrane proteins from Borrelia burgdorferi (Pinne et al., 2006). The general function of ctpA in cell envelope function can be inferred from our earlier study, but the pleiotropic nature of ctpA mutants (Bandara et al., 2005; Gilbert et al., 2007) makes it difficult to define precisely its role in envelope function. Modern cell imaging techniques to describe the cell surface of these mutants may offer new insights into the role of CtpA in envelope function.

Atomic force microscopy (AFM) is the technique of choice to fully characterize the ultrastructure, physical and chemical properties of microbial surfaces (reviewed by 
Dorobantu \& Gray, 2010). The ability to simultaneously probe and image viable specimens at high resolution offers a distinct advantage over scanning electron microscopy (Kaminskyj \& Dahms, 2008). Since AFM is based solely on the interaction of a probe tip with the sample surface, its resolution is only dependent on tip size and shape rather than the diffraction limit inherent to optical microscopy. AFM imaging is capable of producing a topographic surface map with height and lateral resolution at the $\AA-n m$ scale, while force spectroscopy (FS; another AFM mode) can probe whole cell turgor, envelope viscoelasticity and adhesion with $\mathrm{pN}$ sensitivity. AFM and FS have been applied to studying host-microbe interactions (Reis et al., 2006), microbial biofilms (Volle et al., 2008; Díaz et al., 2011), the nano-mechanical properties of whole cells $(\mathrm{Hu}$ et al., 2009; Vadillo-Rodriguez et al., 2009), cellular structures such as pili (Miller et al., 2006), and finer details such as specific molecular distributions on microbial cell surfaces or ligand-receptor interaction forces (Alsteens et al., 2009; Heinisch et al., 2010). Despite the wide applicability of these techniques to microbiology, their application to rhizobia is limited, with only one study describing the interaction of soybean agglutinin with Bradyrhizobium japonicum (Chen et al., 2006).

We used AFM to demonstrate that the surface ultrastructure and roughness, and FS to show that relative surface chemistry, of a $\operatorname{ctp} A$ mutant are altered compared with the wild-type. The aberrant surface roughness of the ctpA mutant led to a further investigation of its ability to form biofilms. We used confocal microscopy and standard biofilm quantification assays to show that the ctpA mutant does not form wild-type biofilms. This report successfully demonstrates the ability of AFM and FS to fully characterize the surface structure and properties of $R$. leguminosarum, and to identify the importance of the ctpA gene in rhizobial biofilm formation.

\section{METHODS}

Bacterial strains, plasmids and media. The wild-type strain used in the study was $R$. leguminosarum biovar viciae 3841 , a spontaneous streptomycin-resistant derivative of strain $R$. leguminosarum bv. viciae strain 300 (Johnston \& Beringer, 1975). The ctpA mutant, strain 3845, and the complemented mutant strain, 3845pKG62, were described by Gilbert et al. (2007). R. leguminosarum strains were cultured using tryptone-yeast (TY) broth (Beringer, 1974) with 1.8, 3.4 (standard) or $3.6 \mathrm{mM} \mathrm{CaCl}_{2}$, or Vincent's minimal medium (VMM; Vincent, 1970) with $10 \mathrm{mM}$ mannitol as a carbon and energy source. Media was supplemented as required with the following concentrations of antibiotics $\left(\mu \mathrm{g} \mathrm{ml}^{-1}\right)$ : streptomycin, 500; neomycin, 100; tetracycline, 5 .

Biofilm cultivation and crystal violet staining for biomass. Biofilms were grown in micro-titre dishes according to the method described by Vanderlinde et al. (2009, 2010). Briefly, bacterial strains from VMM solid medium were resuspended in sterile water to an approximate $\mathrm{OD}_{600}$ of 1.0. The starting inoculum was then diluted 1 in 15 into the appropriate TY medium with $1.8,3.4$ or $3.6 \mathrm{mM} \mathrm{CaCl}_{2}$, and $150 \mu \mathrm{l}$ was added to each well of a cell-culture-treated, polystyrene microtitre plate. Plates were then sealed with Parafilm and incubated at $30{ }^{\circ} \mathrm{C}$ for 48,96 and $144 \mathrm{~h}$ with shaking at 100 r.p.m.
Following incubation, planktonic cells and media were removed, and biofilms were washed once with $200 \mu \mathrm{l}$ sterile distilled water. For quantification of adherent biomass, biofilms were stained with crystal violet according to the method described by O’Toole \& Kolter (1998). Briefly, a $0.4 \%$ crystal violet solution was added to each rinsed well, and plates were incubated at room temperature for $20 \mathrm{~min}$. Wells were then rinsed three times with $200 \mu \mathrm{l}$ sterile distilled $\mathrm{H}_{2} \mathrm{O}$. To measure the amount of adherent biomass, $200 \mu \mathrm{l} 95 \%$ ethanol was added, and the absorbance of the solubilized crystal violet was measured at $550 \mathrm{~nm}$ in a BioTek Synergy HT microplate reader, with Gen5 analysis software (BioTek Instruments).

Biofilm visualization and analysis. Biofilm formation was tested on different substrates, including coverslips made of glass, poly-Llysine (PLL)-coated glass and plastic, mica and dialysis tubing to facilitate AFM imaging. Glass coverslips $(22 \times 22 \mathrm{~mm})$ were cleaned in $1 \mathrm{M} \mathrm{HCl}$ for $1 \mathrm{~min}$, followed by immersion in piranha solution [3:1 (v/v), $\mathrm{H}_{2} \mathrm{SO}_{4}: \mathrm{H}_{2} \mathrm{O}_{2}$ ] for $1 \mathrm{~h}$. After sequential rinsing with deionized water, methanol and acetone, coverslips were air-dried and autoclaved for $20 \mathrm{~min}$. For coated glass, clean glass coverslips were immersed in $0.1 \%$ PLL solution for $10 \mathrm{~min}$ and air-dried overnight, rinsed with sterile deionized water and air-dried. Mica, freshly cleaved with adhesive tape, and dialysis tubing were cut to size $(11 \times 22 \mathrm{~mm})$. Plastic coverslips, mica and dialysis tubing were all sterilized in $70 \%$ ethanol prior to use. R. leguminosarum 3841 and 3845 were cultured in TY broth with $\mathrm{CaCl}_{2}(1.8,3.4$ or $3.6 \mathrm{mM})$, to $\mathrm{OD}_{600} \sim 0.4$. Subsequently, $20 \mathrm{ml}$ of culture was transferred to sterile Petri-dishes, each containing biofilm substrates for incubation at $30{ }^{\circ} \mathrm{C}$. Biofilms were prepared with and without shaking in an incubator or shaking incubator (Lab line; 50 r.p.m.). Substrates were removed from the Petri dishes after 6, 12, 18, 24, 48 and $72 \mathrm{~h}$, and rinsed with VMM

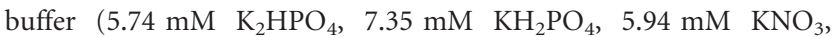
$1.01 \mathrm{mM} \mathrm{MgSO}_{4} \cdot 7 \mathrm{H}_{2} \mathrm{O}, 0.5 \mathrm{mM} \mathrm{CaCl} 2.6 \mathrm{H}_{2} \mathrm{O}$; mimicking VMM ionic strength) to remove planktonic cells.

Samples examined using a light microscope were stained with $0.1 \%$ Toluidine Blue $\mathrm{O}(10 \mathrm{~min})$ and those for confocal microscopy imaging were incubated with calcofluor white $\left(1 \mu \mathrm{g} \mathrm{ml}^{-1}\right)$ in $5 \%$ $\mathrm{KOH}$ solution (1 min), each followed by rinsing with VMM buffer to remove planktonic cells. Coverslips used for confocal imaging were inverted over a clean glass slide and the edge was sealed with nail polish to prevent evaporation.

Biofilms established on different substrate surfaces were evaluated using a light microscope (Olympus BX51) at $400 \times$ magnification, and images were recorded with a digital camera (Olympus DP70). Live biofilms were observed using inverted laser scanning confocal microscopes (Leica SP5 and Zeiss LSM 700).

Sample preparation for AFM. Biofilms formed on glass coverslips over various time periods were rinsed with VMM buffer, fixed $(3.7 \%$ formaldehyde and $0.2 \%$ Triton X-100 in VMM buffer; $20 \mathrm{~min}$, $30{ }^{\circ} \mathrm{C}$ ), rinsed with deionized water to remove excess fixation solution and then air-dried. Individual $R$. leguminosarum and those located at the edge of biofilms were imaged.

Live $R$. leguminosarum grown on dialysis tubing (prepared as above) were cultured for $24 \mathrm{~h}$, rinsed with VMM buffer to remove nonadhering microbes, and attached to a glass coverslip with doublesided tape so one end was sealed and the other left open. Filter paper, cut to a width slightly smaller than the dialysis tubing, was inserted under the open end of the dialysis tubing, attached to the coverslip with adhesive tape (Ma et al., 2005) and transferred onto the AFM sample mount.

AFM. A commercial Explorer 2000 AFM (TopoMetrix, Bruker Instruments) equipped with a dry AFM scanner (model 400006) was used for all measurements. Topography and lateral force images 
were acquired in contact mode using $\mathrm{V}$-shaped silicon nitride tips (MLCT-EXMT-A1, Bruker; nominal spring constant $k=0.05 \mathrm{~N} \mathrm{~m}^{-1}$ ) in contact mode. The same tips were used to collect force curves. Fixed specimens, either individual cells or biofilms thereof, were imaged in air, but for live cell imaging TY broth was supplied to $R$. leguminosarum through the dialysis tubing with drop-wise addition $\left(\sim 50 \mu \mathrm{h} \mathrm{h}^{-1}\right)$ to the underlying filter paper (Ma et al., 2005).

FS. The force of adhesion between the fixed rhizobium and the hydrophilic AFM probe was quantified from force versus distance curves. The spring constant of the cantilever was determined directly prior to force curve acquisition according to Cleveland et al. (1993). The AFM tip was allowed to approach the sample $\left(10 \mu \mathrm{m} \mathrm{s}^{-1}\right)$ until it reached a pre-set position and was then retracted. Surface adhesion values $(\mathrm{nN})$ were measured from the last segment $(\mathrm{e}-\mathrm{f})$ of the retraction cycle (Fig. 1d, h).

Data processing. Light and microscope image contrast was adjusted using Adobe Photoshop. Confocal and AFM images were processed using FV1000 Viewer (version 02.1c) and SPMLab (version 5.01), respectively. Boundaries for measuring biofilm thickness were determined according to fluorescence intensity and excluding any planktonic cells. AFM images were levelled to remove image curvature or background tilt, and a histogram of $\mathrm{Z}$ data was used to adjust image contrast. Average cell surface roughness was calculated using the area analysis function, using the entire cell surface of 2-3 individual bacteria, each from a minimum of two different samples. Roughness was calculated based on the following equation:
$\mathrm{R}_{\alpha}=\frac{1}{n} \sum_{i=0}^{n}\left|Z_{i}-\underline{\bar{Z}}\right|$

where $Z$ is the average height of surface features deviating from the levelling plane, and $Z_{i}$ is the height of single surface features.

A paired Student's $t$-test was used to assess differences in cell size and surface subunit size between the wild-type and $\operatorname{ctp} A$ mutant strains (InStat3, GraphPad). Differences in roughness, adhesion and biofilm thickness for the wild-type and $\operatorname{ctp} A$ mutant strains under normal, $\mathrm{Ca}^{2+}$ supplemented and limited conditions were assessed using oneway ANOVA and a paired Student's $t$-test (InStat3, GraphPad).

\section{RESULTS}

\section{R. leguminosarum morphology and surface characteristics}

Fixed $R$. leguminosarum wild-type and ctpA mutant immobilized on PLL-coated glass coverslips were imaged by AFM to determine their gross morphologies and surface ultrastructures (Fig. 1a, b, e, f). The ctpA mutant strain of $R$. leguminosarum (3845) does not grow on TY agar (Gilbert et al., 2007). When grown in TY broth, the wild-type and $R$. leguminosarum ctpA mutant grow as rods of identical size, but the mutant can also take on a spherical morphology (Table 1). The wild-type $R$. leguminosarum surface has

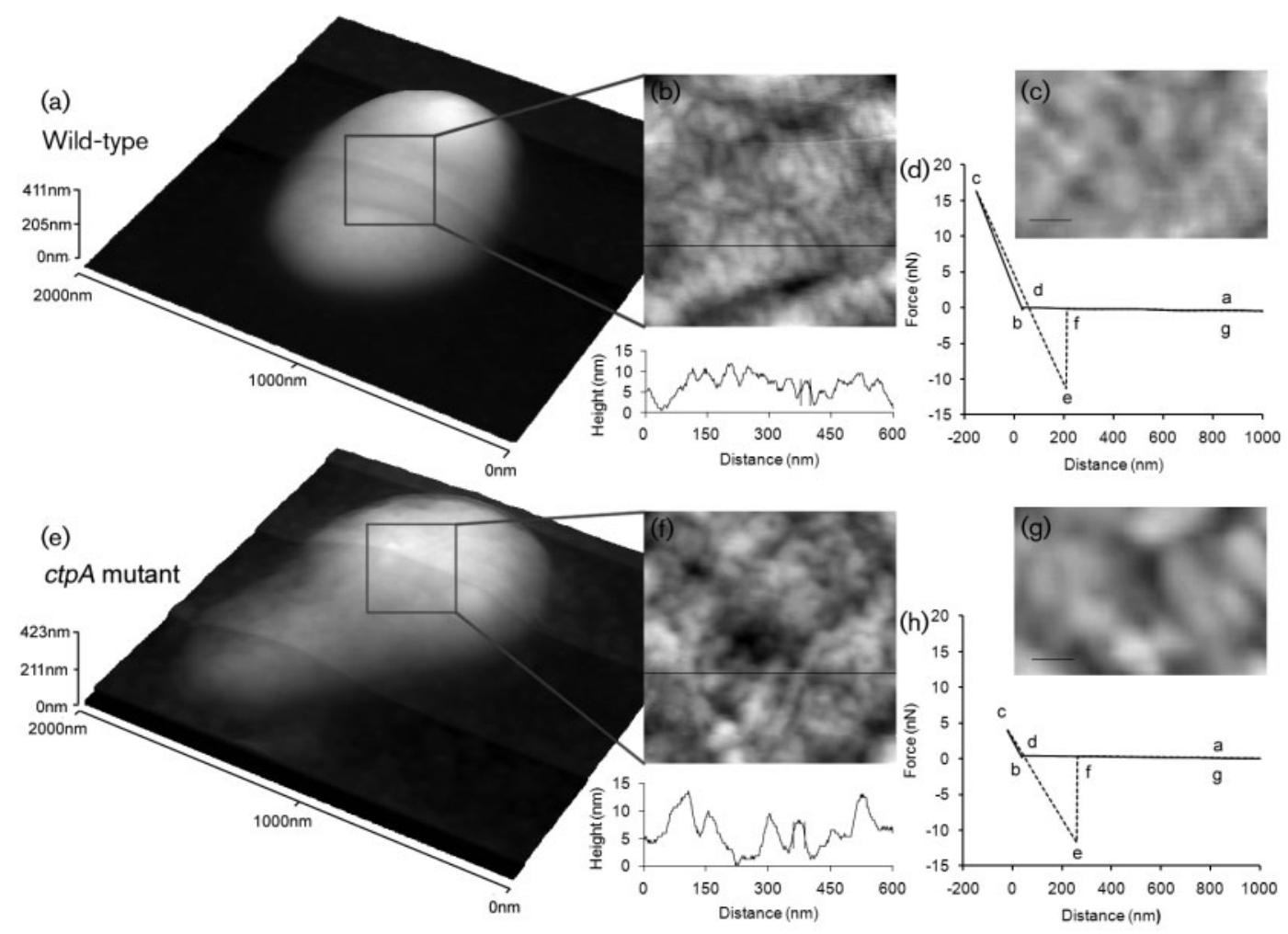

Fig. 1. AFM images of fixed $R$. leguminosarum wild-type $(a-d)$ and $c t p A$ mutant $(e-h)$. Shown are fixed whole cells (a, e) and corresponding surface ultrastructure $(b, f)(600 \times 600 \mathrm{~nm})$ at high resolution compared with those of the live cell surface (c, g), and corresponding force curves $(\mathrm{d}, \mathrm{h})$. Bars, $100 \mathrm{~nm}(\mathrm{c}, \mathrm{g})$. Force curves show the approach (labels i-iii, solid line) and retraction (labels iii-vii, dashed line) cycles. 
Table 1. Morphometry of fixed wild-type $R$. leguminosarum 3841 and the ctpA mutant strain 3845

Data shown are mean \pm SD. NA, Not applicable.

\begin{tabular}{|lccc|}
\hline \multirow{2}{*}{ R. leguminosarum strain } & \multicolumn{2}{c|}{ Cell size $(\boldsymbol{\mu m})$} & Subunit size ${ }^{\star}(\mathbf{n m})$ \\
\cline { 2 - 3 } & Length & Width & \\
\hline Wild-type 3841 & $1.50 \pm 0.20$ & $1.00 \pm 0.06$ & $21 \pm 3 \dagger$ \\
ctpA 3845 rod-shaped $\neq$ & $2.2 \pm 0.8$ & $1.2 \pm 0.4$ & $31 \pm 9 \S$ \\
ctpA 3845 spherical $\neq$ & $1.6 \pm 0.2$ & NA & $40 \pm 10 \S$ \\
\hline
\end{tabular}

${ }^{\star}$ Diameter of smallest dimension.

$\dagger$ The wild-type $R$. leguminosarum had rod-shaped subunits, and the ctpA mutant had unregularly shaped subunits.

¥The ctpA mutant had two distinct morphologies.

$\S$ Differences in surface subunit size between the ctpA mutant and the wild-type $R$. leguminosarum were

statistically significant with a paired Student's $t$-test $(P<0.05)$.

densely packed, elongated surface subunits, composed of small aggregates of surface molecules (Fig. 1), while those of the $\operatorname{ctp} A$ mutant are round but statistically larger $(P<0.0001)$ than the smallest dimension of that of the wild-type and are less well defined, regardless of cell morphology (Table 1). Live specimens show the same results, but with subunits that appear larger than expected (Ma et al., 2005) and with a less even surface distribution (Fig. 1c, g).

Surface roughness is a quantitative assessment of surface texture, defined as the average of the vertical deviations from the nominal surface over a specified surface area. Wild-type $R$. leguminosarum is statistically rougher $(P<0.05)$ compared with the $\operatorname{ctp} A$ mutant strain (Table 2). Depressions apparent on the ctpA mutant cell surface (19 $\pm 4 \mathrm{~nm}$ deep) were statistically larger $(P<0.0001)$ than those observed in the wild-type ( $4 \pm 0.4 \mathrm{~nm}$ deep), indicating variations below or within the cell envelope (Fig. 1a-c, e-g).
The adhesion force between the bacterial surface and the hydrophilic AFM probe was measured using FS (Fig. 1d, h, Table 2). The adhesion forces measured between the hydrophilic AFM probe and the bacteria somewhat mimic that measured between bacteria and the hydrophilic glass coverslips. Approach speed $\left(1,2,5\right.$ or $\left.10 \mu \mathrm{m} \mathrm{s}^{-1}\right)$ did not affect absolute adhesion values, so the fastest rate $\left(10 \mu \mathrm{m} \mathrm{s}^{-1}\right)$ was chosen to reduce lateral contact time with the sample, thus sacrificing the nonlinear region of the force curve. Adhesion forces of the ctpA mutant strain were statistically larger $(P<0.05)$ than those of the wild-type strain.

\section{Effect of $\mathrm{Ca}^{2+}$ on $\mathrm{R}$. leguminosarum surface characteristics}

AFM images revealed that the surface ultrastructures of both wild-type and $\operatorname{ctp} A$ mutant $R$. leguminosarum are altered in

Table 2. Surface subunit, surface roughness and adhesion of fixed wild-type R. leguminosarum 3841 and ctpA mutant 3845

Data shown are mean \pm SD. WT, Wild-type.

\begin{tabular}{|c|c|c|c|c|c|c|}
\hline \multirow[t]{2}{*}{$\mathrm{CaCl}_{2}$ in $\mathrm{TY}$ broth $(\mathrm{mM})$} & \multicolumn{2}{|c|}{ Subunit size $(\mathrm{nm})$} & \multicolumn{2}{|c|}{ Surface roughness $(\mathrm{nm})$} & \multicolumn{2}{|c|}{ Adhesion (nN) } \\
\hline & WT & $\operatorname{ctp} A$ & WT & $\operatorname{ctp} A$ & WT & $\operatorname{ctp} A$ \\
\hline 1.8 & $27 \pm 7 \dagger$ & $25 \pm 3 \neq$ & $2.3 \pm 0.5 \dagger$ & $1.5 \pm 0.1 \neq$ & $8.5 \pm 2.9$ & $5.6 \pm 2.5 \dagger$ \\
\hline 3.4 & $21 \pm 3$ & $31 \pm 9 \S$ & $3.2 \pm 0.4$ & $2.0 \pm 0.3 \S$ & $7.7 \pm 5.1$ & $11.2 \pm 4.6 \$$ \\
\hline 3.6 & $48 \pm 1111$ & $45 \pm 9 \ddagger$ & $4.0 \pm 1.3$ & $2.6 \pm 0.6 \ddagger$ & $19.7 \pm 7.211$ & $17.8 \pm 8.8$ 丰 \\
\hline
\end{tabular}

${ }^{\star}$ Diameter of smallest dimension.

$\dagger$ Differences in wild-type surface subunit size and surface roughness between calcium-limited and standard conditions were statistically significant with a paired Student's $t$-test $(P<0.05)$.

$¥$ Differences in the ctpA mutant surface subunit size, surface roughness and adhesion force between the three different calcium conditions were statistically significant with a paired Student's $t$-test $(P<0.05)$.

$\S$ Differences in surface subunit size, roughness, adhesion and biofilm thickness of the ctpA mutant were statistically significant compared with the wild-type under standard conditions with a paired Student's $t$-test $(P<0.05)$.

IIDifferences in wild-type surface subunit size and adhesion force between calcium standard and supplemented conditions are statistically significant with a paired Student's $t$-test $(P<0.05)$. 
response to varying $\mathrm{Ca}^{2+}$ ion concentrations (Figs 1 and 2). Subunit sizes of the wild-type and ctpA mutant were statistically different under standard conditions, but were statistically identical in size when grown with decreased $(1.8 \mathrm{mM})$ or increased $(3.6 \mathrm{mM})$ calcium chloride concentrations (Table 2). Both the wild-type and $R$. leguminosarum ctpA mutant grown in TY broth with increased calcium chloride $(3.6 \mathrm{mM}$; Fig. 2a, c) had statistically larger $(P<0.05)$ surface subunits than each strain grown in standard TY broth (Table 2, Fig. 1). The normally elongated surface subunits of the wild-type $R$. leguminosarum grown in standard TY broth were round and statistically identical to those of the ctpA mutant strain growth in increased $\mathrm{Ca}^{2+}$ conditions (Table 2).

$\mathrm{Ca}^{2+}$ concentration also had a strong effect on adhesion, for which ranges were similar for wild-type $(\sim 7-20 \mathrm{nN})$ and the ctpA mutant $(\sim 5-18 \mathrm{nN})$. In general, the surface roughness and adhesion of both strains increased as a function of $\mathrm{Ca}^{2+}$ concentration, with the exception of wild-type $R$. leguminosarum, which had statistically identical adhesion values when grown with 1.8 and $3.4 \mathrm{mM}$ calcium chloride (Table 2). Two distinct force curves were observed, and notably the force curve of the ctpA mutant strain grown in the TY broth with $3.6 \mathrm{mM}$ calcium chloride was the only one with a stepwise return to zero deflection (data not shown), indicative of multiple pull-off events detected by the AFM cantilever. In this case, the events likely represent stretching of polymers on the bacterial surface, such as EPS or CPS as the AFM tip was retracted.

\section{Biofilm formation}

Biofilm formation was initiated by the adherence of individual cells to the substrate, and reached a maximum at $24 \mathrm{~h}$. Adhesion was independent of substrate type, although wild-type biofilm accumulation was less apparent on mica (Supplementary Fig. S1, available with the online version of this paper). Adhesion (ctpA mutant) and biofilm formation (wild-type) increased with incubation time (Supplementary Fig. S2). Shaking, a standard practice for biofilms studies, resulted in initially fewer $R$. leguminosarum cells attached to the glass surface, but gradually gave rise to similar biofilms after $24 \mathrm{~h}$ (data not shown).

Confocal microscopy showed that the ctpA mutant biofilm ( $~ 7 \mu \mathrm{m}, 3-4$ bacteria deep) has large areas of continuous cell aggregates lacking detailed internal structures, while the wild-type was capable of forming mature biofilms $(\sim 13 \mu \mathrm{m}$ deep) with channels throughout (Fig. 3). After $72 \mathrm{~h}$ incubation, both the wild-type and ctpA mutant cells in the biofilm began to disperse (Supplementary Fig. S2). The lamellar continuous biofilms of the wild-type strain and $\operatorname{ctp} A$ mutant strain supplemented with mannitol-TY broth were released from the glass surface, but the biofilm of the ctpA mutant strain lacking mannitol supplement appeared as tiny flocci (data not shown). The $\operatorname{ctp} A$ mutant biofilms grown under standard conditions were much more homogeneous than wild-type and were surrounded by a thin transparent layer (data not shown), which stained more efficiently with Coomassie blue (protein) than with Toluidine blue $\mathrm{O}$ (carbohydrate). Wild-type biofilms had a greater number of planktonic cells at their surface (Fig. 3).

R. leguminosarum grown in TY broth with 3.4 (standard), 1.8 or $3.6 \mathrm{mM}$ calcium chloride was used to assess whether $\mathrm{Ca}^{2+}$ ions had an effect on adhesion (Table 2) or biofilm formation (Table 3, Fig. 3). At $3.6 \mathrm{mM}$ calcium chloride, a greater number of cells adhered to glass coverslips for both

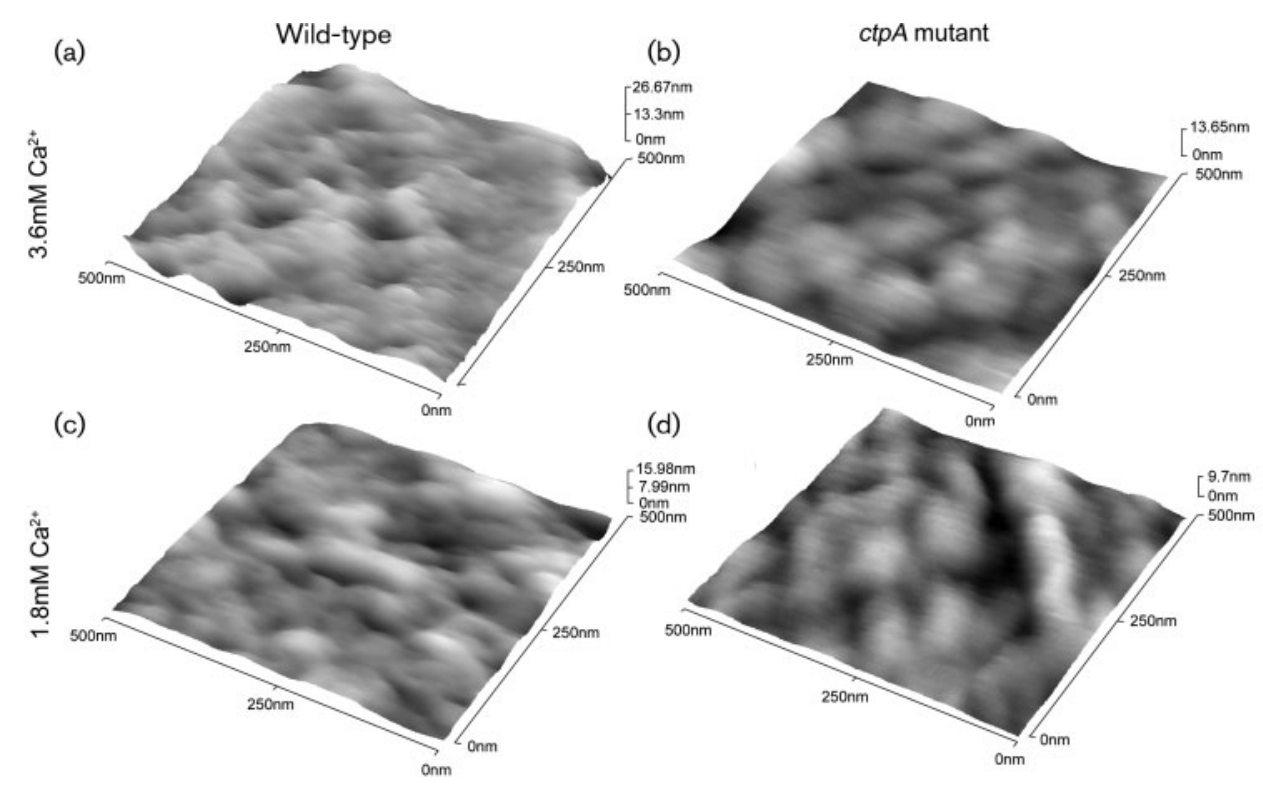

Fig. 2. AFM images of fixed wild-type $R$. leguminosarum $(a, b)$ and the $\operatorname{ctp} A$ mutant $(c, d)$, showing the surface ultrastructure at $3.6 \mathrm{mM}(\mathrm{a}, \mathrm{c})$ and $1.8 \mathrm{mM}(\mathrm{b}, \mathrm{d}) \mathrm{CaCl}_{2}$. 


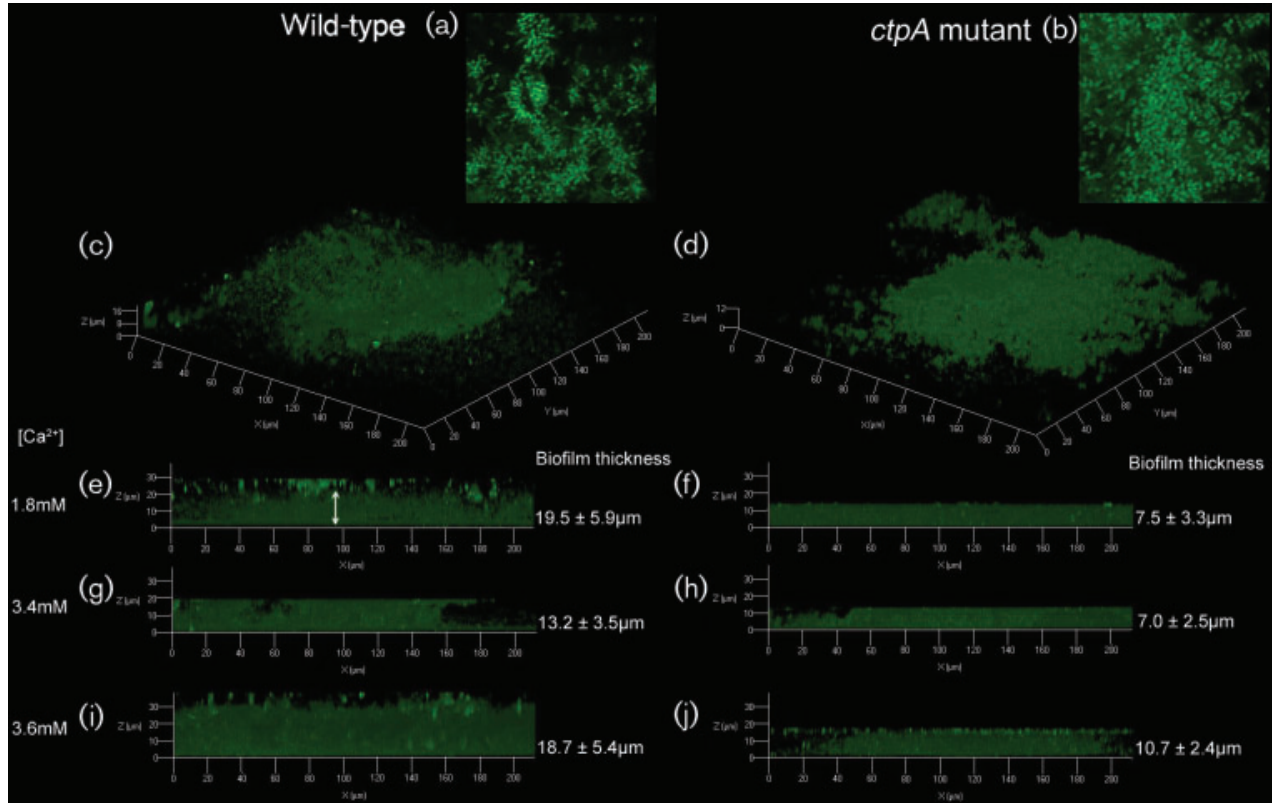

Fig. 3. Confocal microscopy images of live wild-type $R$. leguminosarum $(\mathrm{a}, \mathrm{c}, \mathrm{e}, \mathrm{g}, \mathrm{i})$ and the ctpA mutant $(\mathrm{b}, \mathrm{d}, \mathrm{f}, \mathrm{h}, \mathrm{j})$ biofilms formed on glass coverslips after $48 \mathrm{~h}$ incubation. Average biofilm depth is shown for conditions with $1.8 \mathrm{mM}(\mathrm{e}, \mathrm{f}), 3.4 \mathrm{mM}(\mathrm{g}, \mathrm{h}$, standard) and $3.6 \mathrm{mM}(\mathrm{i}, \mathrm{j}) \mathrm{CaCl}_{2}$ for each strain. The double-headed white arrow shows a typical thickness measurement, excluding planktonic cells. Biofilm thickness $(\mathrm{e}-\mathrm{j})$ was significantly different between the ctpA mutant and wild-type under all conditions $(P<0.05$; Student's $t$-test). A higher contrast version of Fig. 3 is available with the online version of this paper.

types of R. leguminosarum compared with the adhesion in standard TY broth (Supplementary Fig. S3). Wild-type $R$. leguminosarum biofilms were thicker when grown with 1.8 and $3.6 \mathrm{mM}$ calcium chloride compared with standard conditions (Fig. 3e, g, i), the former being statistically identical $(P>0.05)$. On the other hand, biofilms of the ctpA mutant (Fig. 3f, h, j) grown with 1.8 or $3.4 \mathrm{mM}$ calcium chloride were statistically identical $(P>0.05)$, but thinner than those grown with $3.6 \mathrm{mM}$ (Table 2). Mannitol (10 $\mathrm{mM}$ ) supplementation in TY broth restored the ctpA mutant strain biofilm to wild-type levels (Table 3).
At the highest $\mathrm{Ca}^{2+}$ concentrations, deeper biofilms were observed for both wild-type and ctpA mutant strains of $R$. leguminosarum compared with those formed with standard TY broth (Table 2, Fig. 3), which appeared to have large continuous regions that stained with both Toluidine blue O (Supplementary Fig. S3) and Calcofluor white (Fig. 3), but which did not contain bacteria. To estimate the difference in adherent biomass between the wild-type and ctpA mutant stains, we used crystal violet staining (Table 3 ). There was a roughly threefold increase in the amount of crystal violet bound to biofilms formed by the wild-type $R$.

Table 3. Crystal violet staining of adherent biomass under different growth conditions

Crystal violet staining was measured by eluting bound dye with ethanol and reading the $A_{550}$ (see Methods). Data shown are mean \pm SD.

\begin{tabular}{|c|c|c|c|c|}
\hline \multicolumn{2}{|c|}{ Growth condition } & \multicolumn{3}{|c|}{ Strain } \\
\hline Medium & Time (days) & Wild-type (3841) & $\operatorname{ctpA}$ mutant $(3845)$ & Complement (3845pKG62) \\
\hline $\mathrm{TY}+3.4 \mathrm{mM} \mathrm{CaCl}_{2}$ & 2 & $1.047 \pm 0.188$ & $0.368 \pm 0.089^{*}$ & $1.130 \pm 0.238$ \\
\hline $\mathrm{TY}+3.4 \mathrm{mM} \mathrm{CaCl}_{2} / 1 \mathrm{mM}$ mannitol & 2 & $1.623 \pm 0.549$ & $1.348 \pm 0.356$ & $1.730 \pm 0.425$ \\
\hline $\mathrm{TY}+1.8 \mathrm{mM} \mathrm{CaCl}_{2}$ & 2 & $1.795 \pm 0.296$ & $0.428 \pm 0.271^{\star}$ & $1.196 \pm 0.241$ \\
\hline $\mathrm{TY}+3.6 \mathrm{mM} \mathrm{CaCl}_{2}$ & 2 & $1.379 \pm 0.188$ & $0.541 \pm 0.234^{\star}$ & $0.891 \pm 0.322$ \\
\hline $\mathrm{TY}+3.4 \mathrm{mM} \mathrm{CaCl}_{2}$ & 4 & $0.804 \pm 0.235$ & $0.605 \pm 0.118$ & $0.842 \pm 0.235$ \\
\hline $\mathrm{TY}+3.4 \mathrm{mM} \mathrm{CaCl}_{2}$ & 6 & $0.508 \pm 0.105$ & $0.647 \pm 0.046$ & $0.649 \pm 0.098$ \\
\hline
\end{tabular}

${ }^{\star}$ Difference in $A_{550}$ between wild-type and the ctpA mutant was statistically significant with a paired Student's $t$-test $(P<0.05)$. 
leguminosarum compared with those of the ctpA mutant. However, the $\mathrm{Ca}^{2+}$ concentration in TY broth did not have a substantial effect on the amount of stain bound to either the wild-type or mutant strain (Table 3).

\section{DISCUSSION}

CtpA is considered to be a periplasmic protease that is crucial to the maturation of proteins important for cell envelope structure and function. Here we used AFM and FS to further understand the implications of a $\operatorname{ctp} A$ mutation on envelope structure and to continue characterization of CtpA function in alphaproteobacteria, in which its function remains poorly understood.

Our previous work using AFM to study fungal microbes has offered valuable insight into the relationship between wall function, and its ultrastructure and physical properties (Ma et al., 2005, 2006; Kaminskyj \& Dahms, 2008; Paul et al., 2011), and we have applied a similar strategy to the study of $R$. leguminosarum. Images of fixed samples were used to interpret $R$. leguminosarum surface ultrastructure (Fig. 1, Tables 1 and 2). The surface features of the chemically crosslinked fixed samples are more rigidly defined, offering better image contrast than those of live samples that deform under the AFM probe (Ma et al., 2005); nonetheless surface profiles were similar for fixed and live R. leguminosarum (Fig. 1). The AFM tip probes the outer surface of the specimen, making surface features $\left(\mathrm{d}_{\min } \sim 20-40 \mathrm{~nm}\right.$; Fig. 1$)$ attributable to the outermost layer, in this case EPS and/or CPS.

The EPS of R. leguminosarum is similar between strains, consisting of identical conserved octasaccharide backbones containing glucose, glucuronic acid and galactose in a 5:2:1 molar ratio (Robertsen et al., 1981; Skorupska et al., 2006) with branches at the same $\beta$-1,6-linked glucosyl residue. However, patterns of acetyl, pyruvyl and hydroxybutanoyl decoration are strain-dependent (O'Neill et al., 1991; Skorupska et al., 2006). The acidic CPS of each $R$. leguminosarum strain has a similar or identical structure to its EPS. Strains deficient in EPS and/or CPS synthesis have a pleiotropic effect resulting in a significant increase in the synthesis and secretion of cyclic $\beta$-1,2-glucans (Robertsen et al., 1981). Each surface component contributes to the net negative surface charge of this Gram-negative bacterium. EPS was not produced at sufficiently high concentrations to measure for either the wild-type or ctpA mutant grown in TY broth (data not shown), consistent with the repression of EPS production in this growth medium (Borthakur et al., 1986), but this does not necessarily rule out a small contribution of EPS to the surface features observed by AFM. The size of the surface features (20$40 \mathrm{~nm}$ ) compared with the average diameter of a sugar chain $(\sim 1 \mathrm{~nm})$ must therefore reflect backbone branching, and implies that subunits are composed of a higher-order structure of multiple sugar backbones.

Surface roughness effectively quantifies the variance of surface feature height. The wild-type strain is consistently
$50 \%$ rougher $(P<0.05)$ than the $\operatorname{ctp} A$ mutant strain under standard and lower calcium levels (Table 2), suggesting that EPS and/or CPS is arranged differently on the surface of the ctpA mutant, consistent with the larger-sized surface features. With decreased lateral packing, a greater number of polar groups (i.e. hydroxyl group of glucans, other polysaccharides or hydrophilic amino acids of proteins) would be exposed at the cell surface, consistent with $R$. leguminosarum ctpA cells having a greater tendency $(P<0.05)$ for hydrophilic surface adhesion (Table 2).

Calcium is a key component in cell wall organization, stability and permeability (Humphrey \& Vincent, 1962), and is an important factor for maintaining the integrity, stability and function of the outer membrane and cell wall in R. leguminosarum (de Maagd et al., 1989a, b). $\mathrm{Ca}^{2+}$ helps to maintain the outer membrane by shielding the $\mathrm{O}$ antigenic portion of LPS (de Maagd et al. 1989a). Furthermore, adhesin, a $\mathrm{Ca}^{2+}$ binding protein, is considered to be the key protein present on the cell surface of $R$. leguminosarum and is responsible for its preliminary attachment to the leguminous root hairs (Smit et al., 1987; Dardanelli et al., 2003; Mongiardini et al., 2008). Adhesins are extracellular proteins released into the media under $\mathrm{Ca}^{2+}$-limited conditions, but become anchored to the rhizobial surface at higher $\mathrm{Ca}^{2+}$ concentrations. $\mathrm{Ca}^{2+}$ depletion also promotes the release of Omp22 protein in Sinorhizobium (Kim et al., 2005) and can cause the release of LPS (de Maagd et al., 1989a). We therefore expected a rearrangement of the rhizobial surface structure and altered surface characteristics in response to varying $\mathrm{Ca}^{2+}$ levels.

The surface structures of both $R$. leguminosarum strains were altered (Fig. 2) and consequently their surface roughness (Table 2) increased as a function of $\mathrm{Ca}^{2+}$ concentration. Limiting $\mathrm{Ca}^{2+}$ availability had no significant effect on the hydrophilic surface character of wild-type R. leguminosarum, but higher $\mathrm{Ca}^{2+}$ levels made its surface more hydrophilic. For the $\operatorname{ctp} A$ mutant, there was a direct relationship between the surface hydrophilicity and $\mathrm{Ca}^{2+}$ concentration. The greater availability of calcium ions could lead to a net positive charge at the cell surface, potentially affecting adhesion between $R$. leguminosarum and the AFM probe (partial negative charge character). However, even a modest difference in calcium ion concentration $(0.2 \mathrm{mM})$ in the media was capable of changing the size and shape of the surface features and enhanced the hydrophilic properties of both the wild-type (1.5-fold) and ctpA mutant (2.5-fold) strains.

Adhesins fulfil their role only when activated in the presence of excess $\mathrm{Ca}^{2+}$, and here we show a dramatic change in adhesion force only at elevated $\mathrm{Ca}^{2+}$ levels, which were greater than expected for electrostatic interactions between the partial negative charge of the nitrogen lone pairs of the AFM tip and the additional $\mathrm{Ca}^{2+}$ ions. Large electrostatic forces $(3-9 \mathrm{nN})$ are observed in ionic crystals, in which ions are in close proximity $(0.1-0.2 \mathrm{~nm})$, but typical electrostatic forces between the AFM tip within the Debye length 
$(1 \mathrm{~nm})$ of the sample surface are much smaller $(0.001-0.1$ $\mathrm{nN}$ ) (Butt, 1991a, b). Thus, electrostatic force is unlikely to dominate on this length scale, and changes in adhesion and roughness as a function of $\mathrm{Ca}^{2+}$ can be attributed to other molecular forces and alteration of the cell surface structure.

Several studies have demonstrated the importance of a functional cell envelope for proper attachment and biofilm maturation (Fujishige et al., 2006; Russo et al., 2006; Vanderlinde et al., 2009, 2010). Here we provide evidence of a role for CtpA in rhizobial biofilm formation on a hydrophilic surface. We were first interested in determining whether alterations to the cell envelope in a ctpA mutant affected its attachment to a variety of solid surfaces, but neither wild-type nor the ctpA mutant of $R$. leguminosarum showed a preference for abiotic surface type. Adhesion, generally accepted as the initial step in biofilm formation (Fey \& Olson, 2010), was not disturbed in the ctpA mutant, meaning that neither morphology nor molecular surface arrangement appear to influence initial non-specific surface attachment. Indeed, while the ctpA mutant was able to form biofilms, there was a slight preference for attachment to the hydrophilic surfaces (Supplementary Fig. S3), consistent with lower surface roughness and greater hydrophilic character (Table 2). The ctpA gene appears to influence the later stages of biofilm development, maintaining only a thin layer of aggregated rhizobial cells. Mannitol restored the ctpA mutant strain to wild-type levels (Table 3), but it did not affect the number of cells in culture (data not shown), indicating an impact on biofilm matrix formation. Calcium affected biofilm depth for both the wild-type and mutant (Fig. 3), and at increased $\mathrm{Ca}^{2+}$ concentrations, the mutant biofilm was restored to wild-type depth.

Biofilm formation, measured both qualitatively (Supplementary Figs S1-S3) and quantitatively (Tables 2 and 3, Fig. $3)$, was reduced in the $\operatorname{ctp} A$ mutant, demonstrating its importance in biofilm maturation. Once in contact with the surface, the process of permanent attachment is mediated by components of the bacterial cell surface such as LPS, EPS, cell wall anchored proteins, pili, flagella and other outermembrane proteins (Habimana et al., 2007; Manetti et al., 2007; Vu et al., 2009; Bandara et al., 2010; Crawford et al., 2010, Díaz et al., 2011). The interaction of bacterial surface receptors with an abiotic surface can induce increased expression of surface molecules to facilitate specific, permanent adhesion to surrounding cells and surfaces during biofilm structuring, which is mediated by the quorum sensing mechanism (Otto, 2008). The exact role of CtpA in biofilm formation remains to be determined.

\section{Conclusions}

We have characterized the cell surface of $R$. leguminosarum, showing that there are distinct differences between wildtype and $c t p A$ mutant strains. The surface features observed by AFM, most likely attributable to higher-order structures of polysaccharides, were remodelled as a function of $\mathrm{Ca}^{2+}$ concentration. This study shows that higher surface roughness, hydrophilic character and activation by calcium all contribute to the adhesion of $R$. leguminosarum to hydrophilic abiotic surfaces and biofilm formation. The inability of the ctpA mutant to form mature biofilms compared with wild-type $R$. leguminosarum demonstrates that CtpA function is important for biofilm accumulation and maturation.

\section{ACKNOWLEDGEMENTS}

This work was supported by National Science and Engineering Research Council (NSERC) grants to T.E.S.D. (228206-07) and C. K. Y. (288281-2011). J. D. and K. S. L. S. were partially supported by the Faculty of Graduate Studies and Research (University of Regina), and K.S. L.S. and E. M. V. were supported by NSERC Undergraduate Student Research Assistantship and Canada Graduate Scholarship awards, respectively. The authors thank research application specialists, Dr Farid Jalali (Olympus), Dr Reg Sidhu (Leica) and Dr Oliver Prange (Zeiss), for their expert assistance collecting the confocal data.

\section{REFERENCES}

Alsteens, D., Duprés, V., Klotz, S. A., Gaur, N. K., Lipke, P. N. \& Dufrêne, Y. F. (2009). Unfolding individual Als5p adhesion proteins on live cells. ACS Nano 3, 1677-1682.

Bandara, A. B., Sriranganathan, N., Schurig, G. G. \& Boyle, S. M. (2005). Carboxyl-terminal protease regulates Brucella suis morphology in culture and persistence in macrophages and mice. J Bacteriol 187, 5767-5775

Bandara, H. M., Lam, O. L., Watt, R. M., Jin, L. J. \& Samaranayake, L. P. (2010). Bacterial lipopolysaccharides modulate in vitro biofilm formation of Candida species. J Med Microbiol 59, 1225-1234.

Beringer, J. E. (1974). R factor transfer in Rhizobium leguminosarum. J Gen Microbiol 84, 188-198.

Borthakur, D., Barber, C. E., Lamb, J. W., Daniels, M. J., Downie, J. A. \& Johnston, A. W. B. (1986). A mutation that blocks exopolysaccharide synthesis prevents nodulation of peas by Rhizobium leguminosarum but not of beans by $R$. phaseolii and is corrected by cloned DNA from Rhizobium or the phytopathogen Xanthomonas. Mol Gen Genet 203, 320-323.

Butt, H. J. (1991a). Electrostatic interaction in atomic force microscopy. Biophys J 60, 777-785.

Butt, H. J. (1991b). Measuring electrostatic, van der Waals, and hydration forces in electrolyte solutions with an atomic force microscope. Biophys J 60, 1438-1444.

Carlson, R. W., Reuhs, B. L., Forsberg, L. S. \& Kannenberg, E. L. (1999). Rhizobial cell surface carbohydrates: their structures, biosynthesis and functions. In Genetics of Bacterial Polysaccharides, pp. 53-90. Edited by J. B. Goldberg. Boca Raton: CRC Press.

Chen, J. L., Lin, S. \& Lin, L. P. (2006). Rhizobial surface biopolymers and their interaction with lectin measured by atomic force microscopy. World J Microb Biot 22, 565-570.

Cleveland, J. P., Manne, S., Bocek, D. \& Hansma, P. K. (1993). Nondestructive method for determining the spring constant of cantilevers for scanning force microscopy. Rev Sci Instrum 64, 403405.

Crawford, R. W., Reeve, K. E. \& Gunn, J. S. (2010). Flagellated but not hyperfimbriated Salmonella enterica serovar Typhimurium attaches to and forms biofilms on cholesterol-coated surfaces. J Bacteriol 192, 2981-2990. 
Dardanelli, M., Angelini, J. \& Fabra, A. (2003). A calcium-dependent bacterial surface protein is involved in the attachment of rhizobia to peanut roots. Can J Microbiol 49, 399-405.

de Maagd, R. A., de Rijk, R., Mulders, I. H. \& Lugtenberg, B. J. (1989a). Immunological characterization of Rhizobium leguminosarum outer membrane antigens by use of polyclonal and monoclonal antibodies. J Bacteriol 171, 1136-1142.

de Maagd, R. A., Wientjes, F. B. \& Lugtenberg, B. J. (1989b). Evidence for divalent cation $\left(\mathrm{Ca}^{2+}\right)$-stabilized oligomeric proteins and covalently bound protein-peptidoglycan complexes in the outer membrane of Rhizobium leguminosarum. J Bacteriol 171, 3989-3995.

Díaz, C., Schilardi, P. L., Salvarezza, R. C. \& Fernández Lorenzo de Mele, M. (2011). Have flagella a preferred orientation during early stages of biofilm formation? AFM study using patterned substrates. Colloids Surf B Biointerfaces 82, 536-542.

Dorobantu, L. S. \& Gray, M. R. (2010). Application of atomic force microscopy in bacterial research. Scanning 32, 74-96.

Fey, P. D. \& Olson, M. E. (2010). Current concepts in biofilm formation of Staphylococcus epidermidis. Future Microbiol 5, 917-933.

Fujishige, N. A., Kapadia, N. N., De Hoff, P. L. \& Hirsch, A. M. (2006). Investigations of Rhizobium biofilm formation. FEMS Microbiol Ecol 56, 195-206.

Gilbert, K. B., Vanderlinde, E. M. \& Yost, C. K. (2007). Mutagenesis of the carboxy terminal protease CtpA decreases desiccation tolerance in Rhizobium leguminosarum. FEMS Microbiol Lett 272, 65-74.

Habimana, O., Le Goff, C., Juillard, V., Bellon-Fontaine, M. N., Buist, G., Kulakauskas, S. \& Briandet, R. (2007). Positive role of cell wall anchored proteinase PrtP in adhesion of lactococci. BMC Microbiol 7, 36.

Hara, H., Nishimura, Y., Kato, J., Suzuki, H., Nagasawa, H., Suzuki, A. \& Hirota, Y. (1989). Genetic analyses of processing involving Cterminal cleavage in penicillin-binding protein 3 of Escherichia coli. $J$ Bacteriol 171, 5882-5889.

Hara, H., Yamamoto, Y., Higashitani, A., Suzuki, H. \& Nishimura, Y. (1991). Cloning, mapping, and characterization of the Escherichia coli prc gene, which is involved in C-terminal processing of penicillinbinding protein 3. J Bacteriol 173, 4799-4813.

Heinisch, J. J., Duprés, V., Alsteens, D. \& Dufrêne, Y. F. (2010). Measurement of the mechanical behavior of yeast membrane sensors using single-molecule atomic force microscopy. Nat Protoc 5, 670677.

Hoge, R., Laschinski, M., Jaeger, K. E., Wilhelm, S. \& Rosenau, F. (2011). The subcellular localization of a C-terminal processing protease in Pseudomonas aeruginosa. FEMS Microbiol Lett 316, 23-30.

Hu, M., Wang, J., Zhao, H., Dong, S. \& Cai, J. (2009). Nanostructure and nanomechanics analysis of lymphocyte using AFM: from resting, activated to apoptosis. J Biomech 42, 1513-1519.

Humphrey, B. \& Vincent, J. M. (1962). Calcium in cell walls of Rhizobium trifolii. J Gen Microbiol 29, 557-561.

Johnston, A. W. \& Beringer, J. E. (1975). Identification of the rhizobium strains in pea root nodules using genetic markers. $J$ Gen Microbiol 87, 343-350.

Kaminskyj, S. G. W. \& Dahms, T. E. S. (2008). High spatial resolution surface imaging and analysis of fungal cells using SEM and AFM. Micron 39, 349-361.

Kim, W. S., Sun-Hyung, J., Park, R. D., Kim, K. Y. \& Krishnan, H. B. (2005). Sinorhizobium fredii USDA257 releases a $22-\mathrm{kDa}$ outer membrane protein (Omp22) to the extracellular milieu when grown in calcium-limiting conditions. Mol Plant Microbe Interact 18, 808-818.

Lepek, V. C. \& D’Antuono, A. L. (2005). Bacterial surface polysaccharides and their role in the rhizobia-legume association. Lotus Newsletter 35, 93-105.
Ma, H., Snook, L. A., Kaminskyj, S. G. W. \& Dahms, T. E. S. (2005). Surface ultrastructure and elasticity in growing tips and mature regions of Aspergillus hyphae describe wall maturation. Microbiology 151, 3679-3688.

Ma, H., Snook, L. A., Tian, C., Kaminskyj, S. G. W. \& Dahms, T. E. S. (2006). Fungal surface remodelling visualized by atomic force microscopy. Mycol Res 110, 879-886.

Manetti, A. G., Zingaretti, C., Falugi, F., Capo, S., Bombaci, M., Bagnoli, F., Gambellini, G., Bensi, G., Mora, M. \& other authors (2007). Streptococcus pyogenes pili promote pharyngeal cell adhesion and biofilm formation. Mol Microbiol 64, 968-983.

Miller, E., Garcia, T., Hultgren, S. \& Oberhauser, A. F. (2006). The mechanical properties of $E$. coli type 1 pili measured by atomic force microscopy techniques. Biophys J 91, 3848-3856.

Mongiardini, E. J., Ausmees, N., Pérez-Giménez, J., Julia Althabegoiti, M., Ignacio Quelas, J., López-García, S. L. \& Lodeiro, A. R. (2008). The rhizobial adhesion protein RapAl is involved in adsorption of rhizobia to plant roots but not in nodulation. FEMS Microbiol Ecol 65, 279-288.

O'Neill, M. A., Darvill, A. G. \& Albersheim, P. (1991). The degree of esterification and points of substitution by $O$-acetyl and $O$-(3hydroxybutanoyl) groups in the acidic extracellular polysaccharides secreted by Rhizobium leguminosarum biovars viciae, trifolii, and phaseoli are not related to host range. J Biol Chem 266, 9549-9555.

O'Toole, G. A. \& Kolter, R. (1998). Flagellar and twitching motility are necessary for Pseudomonas aeruginosa biofilm development. Mol Microbiol 30, 295-304.

Otto, M. (2008). Staphylococcal biofilms. Curr Top Microbiol Immunol 322, 207-228.

Paul, B. C., El-Ganiny, A. M., Abbas, M., Kaminskyj, S. G. W. \& Dahms, T. E. S. (2011). Quantifying the importance of galactofuranose in Aspergillus nidulans hyphal wall surface organization by atomic force microscopy. Eukaryot Cell 10, 646-653.

Pinne, M., Denker, K., Nilsson, E., Benz, R. \& Bergström, S. (2006). The BBA01 protein, a member of paralog family 48 from Borrelia burgdorferi, is potentially interchangeable with the channel-forming protein P13. J Bacteriol 188, 4207-4217.

Reis, Y., Cortes, H., Viseu Melo, L., Fazendeiro, I., Leitão, A. \& Soares, H. (2006). Microtubule cytoskeleton behavior in the initial steps of host cell invasion by Besnoitia besnoiti. FEBS Lett 580, 46734682.

Robertsen, B. K., Aman, P., Darvill, A. G., McNeil, M. \& Albersheim, P. (1981). Host-symbiont interactions: V. The structure of acidic extracellular polysaccharides secreted by Rhizobium leguminosarum and Rhizobium trifolii. Plant Physiol 67, 389-400.

Russo, D. M., Williams, A., Edwards, A., Posadas, D. M., Finnie, C., Dankert, M., Downie, J. A. \& Zorreguieta, A. (2006). Proteins exported via the PrsD-PrsE type I secretion system and the acidic exopolysaccharide are involved in biofilm formation by Rhizobium leguminosarum. J Bacteriol 188, 4474-4486.

Silhavy, T. J., Kahne, D. \& Walker, S. (2010). The bacterial cell envelope. Cold Spring Harb Perspect Biol 2, a000414.

Skorupska, A., Janczarek, M., Marczak, M., Mazur, A. \& Król, J. (2006). Rhizobial exopolysaccharides: genetic control and symbiotic functions. Microb Cell Fact 5, 7.

Smit, G., Kijne, J. W. \& Lugtenberg, B. J. (1987). Involvement of both cellulose fibrils and a $\mathrm{Ca}^{2+}$-dependent adhesin in the attachment of Rhizobium leguminosarum to pea root hair tips. J Bacteriol 169, 42944301.

Soto, M. J., Domínguez-Ferreras, A., Pérez-Mendoza, D., Sanjuán, J. \& Olivares, J. (2009). Mutualism versus pathogenesis: the give-andtake in plant-bacteria interactions. Cell Microbiol 11, 381-388. 
Vadillo-Rodriguez, V., Schooling, S. R. \& Dutcher, J. R. (2009). In situ characterization of differences in the viscoelastic response of individual Gram-negative and Gram-positive bacterial cells. J Bacteriol 191, 5518-5525.

Vanderlinde, E. M., Muszynski, A., Harrison, J. J., Koval, S. F., Foreman, D. L., Ceri, H., Kannenberg, E. L., Carlson, R. W. \& Yost, C. K. (2009). Rhizobium leguminosarum biovar viciae 3841, deficient in 27-hydroxyoctacosanoate-modified lipopolysaccharide, is impaired in desiccation tolerance, biofilm formation and motility. Microbiology 155, 3055-3069.

Vanderlinde, E. M., Harrison, J. J., Muszyński, A., Carlson, R. W., Turner, R. J. \& Yost, C. K. (2010). Identification of a novel ABC transporter required for desiccation tolerance, and biofilm formation in Rhizobium leguminosarum bv. viciae 3841. FEMS Microbiol Ecol 71, 327-340.
Vincent, V. M. (1970). A Manual for the Practical Study of Root-nodule Bacteria (IBP Handbook no. 15). Oxford: Blackwell Scientific Publications.

Vlassak, K. M. \& Vanderleyden, J. (1997). Factors influencing nodule occupancy by inoculant rhizobia. Crit Rev Plant Sci 16, 163-219.

Volle, C. B., Ferguson, M. A., Aidala, K. E., Spain, E. M. \& Núñez, M. E. (2008). Spring constants and adhesive properties of native bacterial biofilm cells measured by atomic force microscopy. Colloids Surf B Biointerfaces 67, 32-40.

Vu, B., Chen, M., Crawford, R. J. \& Ivanova, E. P. (2009). Bacterial extracellular polysaccharides involved in biofilm formation. Molecules 14, 2535-2554.

Edited by: W. Achouak 